\title{
RFID Based Traffic Offence Fining System
}

\author{
Surya Deo Chaudhary, Alka Singh, Kanika Jindal
}

\begin{abstract}
This paper proposes an RFID based traffic offence fining system that automatically detects the defaulter who breaks the traffic signal. It comprises of an RFID reader for detecting the vehicle which breaks the traffic signal, a microcontroller for processing and collecting the data of defaulter and a GSM module for sending the message on defaulters registered mobile number and regional transport office (RTO). This proposed system is very unique and eliminate the traditional use of paper pen fining system.
\end{abstract}

Keywords RFID, Regional Transport Office (RTO), GSM module, microcontroller.

\section{INTRODUCTION}

In present times the challan in our country is paid to the regional transport office manually. The fining or challan system is based on pen and paper format in which the fine is paid by defaulter by going to RTO office. This process of paying fine takes a lot of time and sometimes leads to corruption [1]. The person who breaks the rule gives the fine to the traffic police man something else and the traffic policeman give this fine to government something else [2],[3]. However, there exist no such system that can be employed to reduce such problems in traffic. Meanwhile the increasing of traffic has become a significant event in the nationwide interest. Therefore, keeping in mind the previously occurring problems this paper discloses about a new system in which if the vehicle crosses the red light then the e-challan or fine will automatically generated and notify the defaulter through the SMS [4]. Also, the message will be transferred to regional transport office. The proposed system is a new and unique as it saves a lot of time of driver who breaks the rule and reduces the chance of corruption. RFID based fining system eliminates the traditional pen and paper and makes the system green. The increase in complexity in paying fine is also reduced by proposed system. Due to the fast and reckless driving of the vehicle there exist many road accidents by crossing of red-light signal. Thus, the proposed system eradicates these road accidents by alerting the driver regarding traffic rules [5]. The RFID based fining system detects the vehicle when it jumps the red-light signal. The detected signal is sends to a microcontroller that receive and process the detected signal. After processing, it sends the message to the defaulter registered number that is associated

Revised Version Manuscript Received on 10 September, 2019.

Dr. Surya Deo Chaudhary, Department of Electronics \& Technology, Noida, U.P. India. (email: researchnietip@gmail.com)

Alka Singh, Department of Information Technology, Noida Institute of Engineering and Technology, Noida, U.P. India. (email: researchnietip@gmail.com)

Kanika Jindal, Department of Electronics \& Communication Engineering, Noida Institute of Engineering and Technology, Noida, U.P. India. (email: researchnietip@gmail.com) Communication Engineering, Noida Institute of Engineering and

with the vehicle and also sends the defaulter details to regional transport officer.

\section{LITERATURE REVIEW}

Conventionally, various systems are developed that provide an automatic collection of toll payment using RFID [6]. In this system the toll tax is automatically deducted from the user's account when the user's vehicle passes from the toll tax gate. The one-time password is sent to user registered mobile phone for granting a permission to pay the toll tax. This system also detects the drunk driver by the gas sensor installed near the steering. If the driver is over drunk then the speed of the vehicle is automatically reduced.

Another RFID based system relates to an automatic identification of vehicle and management system [7]. This system is capable of receiving and transmitting the data for automatic identification of vehicle. It consists of camera for capturing the vehicle number and sends the captured data to the RTO.

\section{PROPOSED SYSTEM}

An RFID based traffic offence fining system comprises of a power source for supplying power to all the component of the system, a rectifier unit provides a $12 \mathrm{v}$ dc power to the $\mathrm{dc}$ jack, capacitor $\mathrm{c} 1, \mathrm{c} 2, \mathrm{c} 3$ and $\mathrm{c} 4$ act as smoothing filter to smoothen the dc power, LED is connected for displaying the data of defaulter. A power switch is also available to turnoff the power.

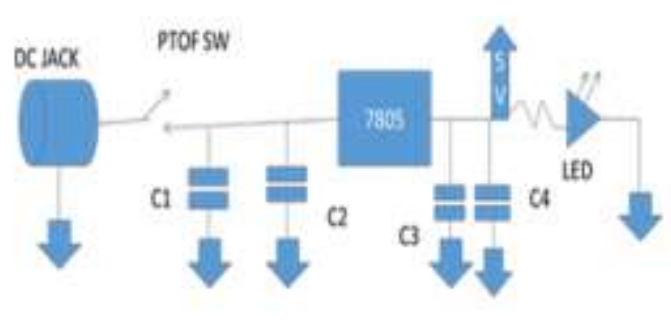

Fig.1 Power Unit

The controlling module is most crucial part of the proposed system. It comprises of an RFID reader for detecting the vehicle which jump off the red light signal and breaks the traffic rule, a microcontroller is installed in the system which connects all the component for controlling and monitoring the whole system, a relay for transmitting the 
signal to the GSM, plurality of LEDs for alerting purposes.

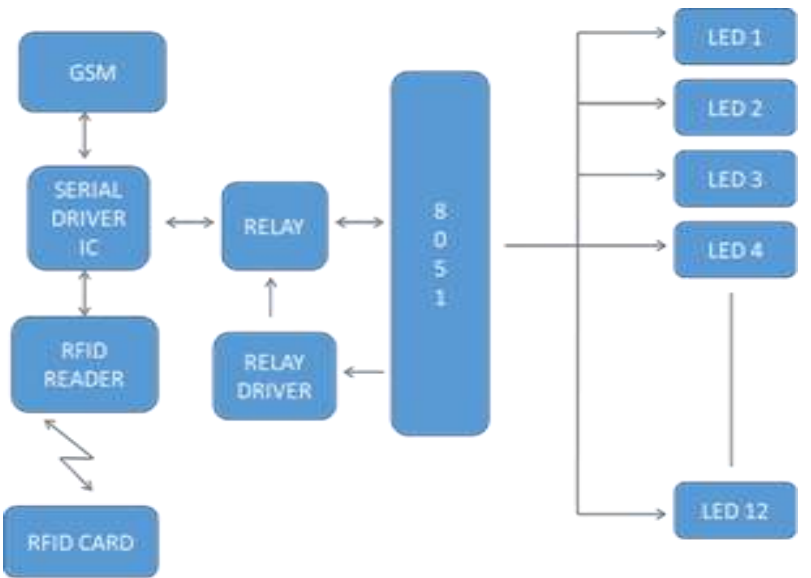

Fig.2 Controlling Module

When the vehicle crosses the red-light traffic signal by breaking traffic rule, the RFID reader detects the rule breaking vehicle and sends the signal to microcontroller and the microcontroller after gathering the details of defaulter, transmit the signal to GSM module via relay. The GSM module sends the signal to the defaulter registered mobile number and to the RTO. The transmitted message that is send to the defaulter and regional transport office contains the vehicle number of defaulter and the amount that has to be paid by the defaulter for breaking the traffic signal.

\section{RESULT AND DISCUSSION}

The prototype of the proposed system is shown in fig. 3 and the circuit of the proposed system is shown in fig.4. The hardware is successfully tested and all the component such as microcontroller, relay, GSM module and RFID reader are ready to do their work on an appropriate time. When the vehicle crosses the road by breaking the traffic signal, the RFID reader attached to the signal light detects the crossing vehicle and sends the signal to the microcontroller. The microcontroller after processing gathers the detail of the defaulter and sends these details to defaulter and regional transport office (RTO) by messaging on defaulter's registered mobile number.

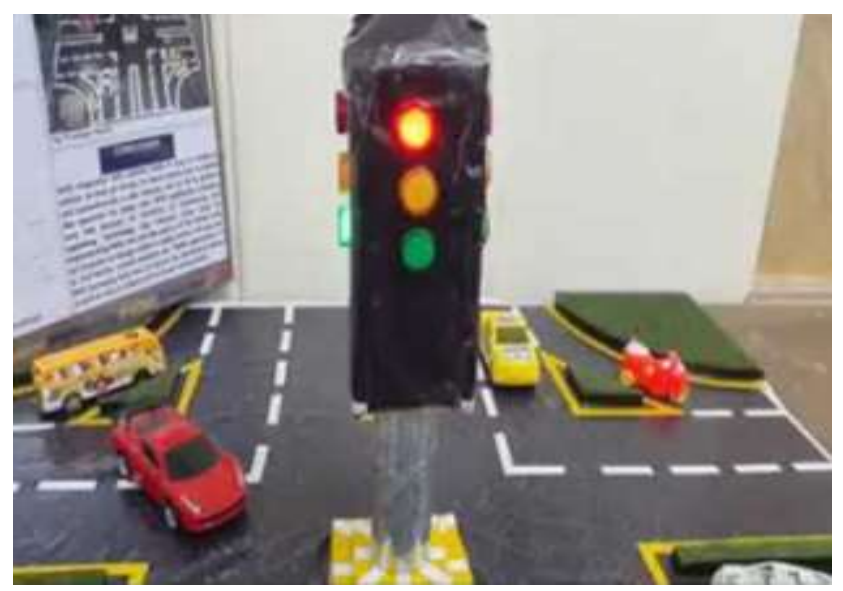

Fig.3 RFID Based Traffic Offence Fine System

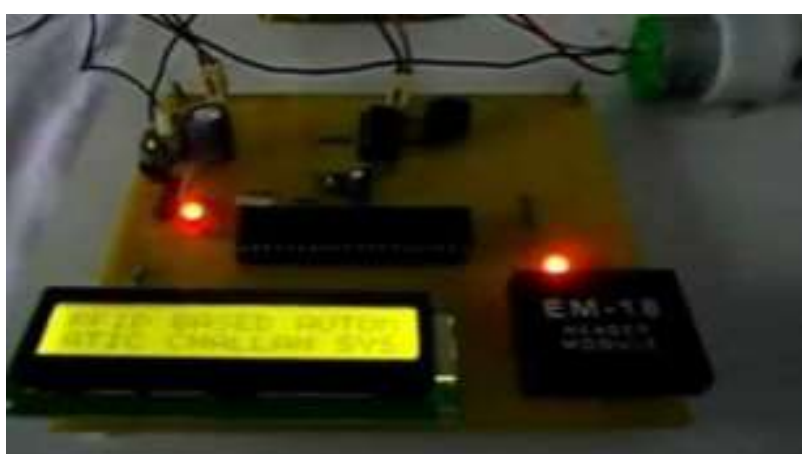

Fig.4 Working Model of RFID based System

\section{CONCLUSION}

The prototype of proposed system is successfully designed and tested. It is a unique RFID based automatic fining system that detects and fine the person who breaks the traffic signal. The proposed system eliminates the number of road accident that occurs due to the fault of reckless driver. Automatic RFID based system detects the vehicle that crosses the red light through RFID reader and sends the detected signal to microcontroller. The microcontroller after processing, collects the information of the defaulter and made an estimate fine and send it to the defaulter and regional transport office through GSM module in the form of messages. Through this process the defaulter knows about their fault which he/she had done while crossing the signal light. Thus, reduces the change of road accident by alerting the defaulter about their mistakes.

\section{REFERENCES}

1. P. Barford, J. Kline, D. Plonka, and A. Ron, "A signal analysis of network traffic anomalies," 2004.

2. F. V. Webster, Traffic signal settings. 1958.

3. A. Jewalikar, T. Jadhav, and R. Haridas, "Bio Metric based Challan System for Smart Local Transport in India,” Int. J. Comput. Appl., 2018.

4. S. Chouksey and S. Sirsikar, "An Efficient And Economical Solution For Future Traffic Management System Using RFID,” 2016.

5. B. B. Lonkar, M. R. Sayankar, and P. D. Charde, "Design and Monitor Smart Automatic Challan Generation Based on RFID Using GPS and GSM," 2018.

6. A. Kumar, N. Anusha, and B. S. S. V. Prasad, "Automatic toll payment, alcohol detection, load and vehicle information using Internet of things \& mailing system," in Proceedings of 2017 International Conference on Intelligent Computing and Control, I2C2 2017, 2018.

7. C. H. Li, "Automatic vehicle identification (AVI) system Based on RFID," in Proceedings - 2010 International Conference on Anti-Counterfeiting, Security and Identification, 2010 ASID, 2010. 